\title{
Production of Boron Carbide Reinforced 2024 Aluminum Matrix Composites by Mechanical Alloying
}

\author{
Cun-Zhu Nie ${ }^{1}$, Jia-Jun Gu${ }^{1}$, Jun-Liang Liu² and Di Zhang ${ }^{1, *}$ \\ ${ }^{1}$ State Key Laboratory of Metal Matrix Composites, Shanghai JiaoTong University, Shanghai 200030, P.R. China \\ ${ }^{2}$ Baosteel Research Institute, Baoshan Iron \& Steel Co. Ltd., Shanghai 201900, P.R. China
}

Boron carbide particulates reinforced 2024 Aluminum matrix composites were fabricated by mechanical alloying-hot extrusion technology successfully. The morphology and microstructure of $\mathrm{B}_{4} \mathrm{C}_{\mathrm{p}} / 2024 \mathrm{Al}$ composite were investigated by optical microscopy (OM), scanning electron microscopy (SEM) and transmission electron microscopy (TEM). A clean interface of $\mathrm{B}_{4} \mathrm{C}$ between aluminum was obtained in this experiment, and matrix alloy revealed the typical microstructure of high energy milling with average grain size about $300 \mathrm{~nm}$. Nanosized oxide and carbide formed after the composites subjected to high energy milling and hot consolidation process. The yield strength and Young's modulus values were improved significantly over the monolithic 2024 alloy. [doi:10.2320/matertrans.48.990]

(Received November 6, 2006; Accepted February 28, 2007; Published April 25, 2007)

Keywords: $B_{4} C$ particulate reinforced aluminum matrix composites, mechanical alloying, microstructure, performance

\section{Introduction}

Particulate reinforced aluminum matrix composites (PRAMC) have received considerable attention because of their high specific strength, high specific modulus, low CTE (coefficient of thermal expansion) value and good wear resistance. $^{1,2)}$ The PRAMCs were usually produced by powder metallurgy and casting route. ${ }^{3-6)}$ Powder metallurgy techniques have advantage over casting method by eliminating the segregation typical of casting. So blending the mixture to achieve the homogenous distribution of reinforcement into base alloy became a key step of powder metallurgy process.

Mechanical alloying/milling became an effective way to improve reinforcement distribution throughout the matrix. Some research works ${ }^{7-9)}$ show that reinforcements such as $\mathrm{SiC}$ particles can be successfully incorporated into aluminum matrix using MA technique. The property of composites was improved by the uniform distribution of reinforcement and the refinement of sub-grain size.

Boron Carbide $\left(\mathrm{B}_{4} \mathrm{C}\right)$ has many attractive properties, such as low specific gravity, high hardness value, high elastic modulus value and neutron absorption, which help $\mathrm{B}_{4} \mathrm{C}$ to be widely used as cermets and armor materials. ${ }^{10,11)}$ As a promising reinforcement of PRAMC, $\mathrm{B}_{4} \mathrm{C}$ received little attentions over its counterparts such as $\mathrm{SiC}$ and $\mathrm{Al}_{2} \mathrm{O}_{3}$. From limited information of $\mathrm{B}_{4} \mathrm{C}$ reinforced aluminum matrix composites, there are several research works mainly focused on the wettability and chemical reaction between aluminum and boron carbide. ${ }^{12,13)} \mathrm{Hu}$ et al. $^{14)}$ analyzed the microstructure and interface of $\mathrm{B}_{4} \mathrm{C}_{\mathrm{P}} / \mathrm{Al}$ composites fabricated by Boralyn process, but the data of mechanical property about the composites are not reported yet.

This paper aims to analyze the microstructure evolution of $\mathrm{B}_{4} \mathrm{C}_{\mathrm{p}} / \mathrm{Al}$ composites during mechanical alloying and the microstructure, mechanical property of the composites prepared by MA-hot extrusion technique. We explore a method to produce the $\mathrm{B}_{4} \mathrm{C}$ particulate reinforced aluminum

*Corresponding author, E-mail: zhangdi@sjtu.edu.cn matrix composites by combining the MA and hot extrusion technique.

\section{Experimental Procedure}

\subsection{Material}

Inert gas atomized $2024 \mathrm{Al}$ powders with average particle size of $27 \mu \mathrm{m}$ were used as the matrix alloy, and the $2024 \mathrm{Al}$ powders with a near spherical morphology. Boron carbide powders with a narrow size distribution between 4 and $10 \mu \mathrm{m}$ (mean particle size $7 \mu \mathrm{m}$ ) were added as reinforcements.

\subsection{Fabrication of the composites}

Aluminum and $\mathrm{B}_{4} \mathrm{C}$ powders were mechanically alloyed in planetary milling apparatus. The AISI 304L milling vial and balls were selected as the milling medium. Milling parameters were selected as follows: ball to powder ratio $20: 1$, sun-disk rotation speed $250 \mathrm{rpm}$, planetary-disk rotation speed $420 \mathrm{rpm}$, with Argon atmosphere protection, and with stearic acid $\left(\mathrm{CH}_{3}\left(\mathrm{CH}_{2}\right){ }_{16} \mathrm{CO}_{2} \mathrm{H}\right)$ addition as process control agent (PCA). The $\mathrm{B}_{4} \mathrm{C}_{\mathrm{P}} / 2024 \mathrm{Al}$ composite mixtures which milled 5 hrs were loaded into a steel die and cold pressed at $400 \mathrm{MPa}$, hot-pressed at $570^{\circ} \mathrm{C}$ with a pressure of $300 \mathrm{MPa}$, so a billet with a diameter of $38 \mathrm{~mm}$ and a height of $50 \mathrm{~mm}$ was obtained. The hot press billet then hot-extruded at $480^{\circ} \mathrm{C}$ by a extrusion ratio of $10: 1$ used the graphite as lubricant. The monolithic 2024 alloy has an exact hot consolidation process similar to composite as a reference.

\subsection{Examination of microstructures and mechanical properties}

The microstructure of the $\mathrm{B}_{4} \mathrm{C}_{\mathrm{P}} / 2024 \mathrm{Al}$ composite was characterized by optical microscopy $(\mathrm{OM})$ and transmission electron microscopy (TEM). The slices of $0.3 \mathrm{~mm}$ were cut perpendicular to the extrusion direction using electrical discharge machining method. Then the slice was mechanical polished to a thickness about $60 \mu \mathrm{m}$ and dimpled to about $20 \mu \mathrm{m}$ in the center of the disk; finally ion milled using an ion miller. The extruded rod machined to the tensile specimen with a gauge diameter and length of 4 and $30 \mathrm{~mm}$, 

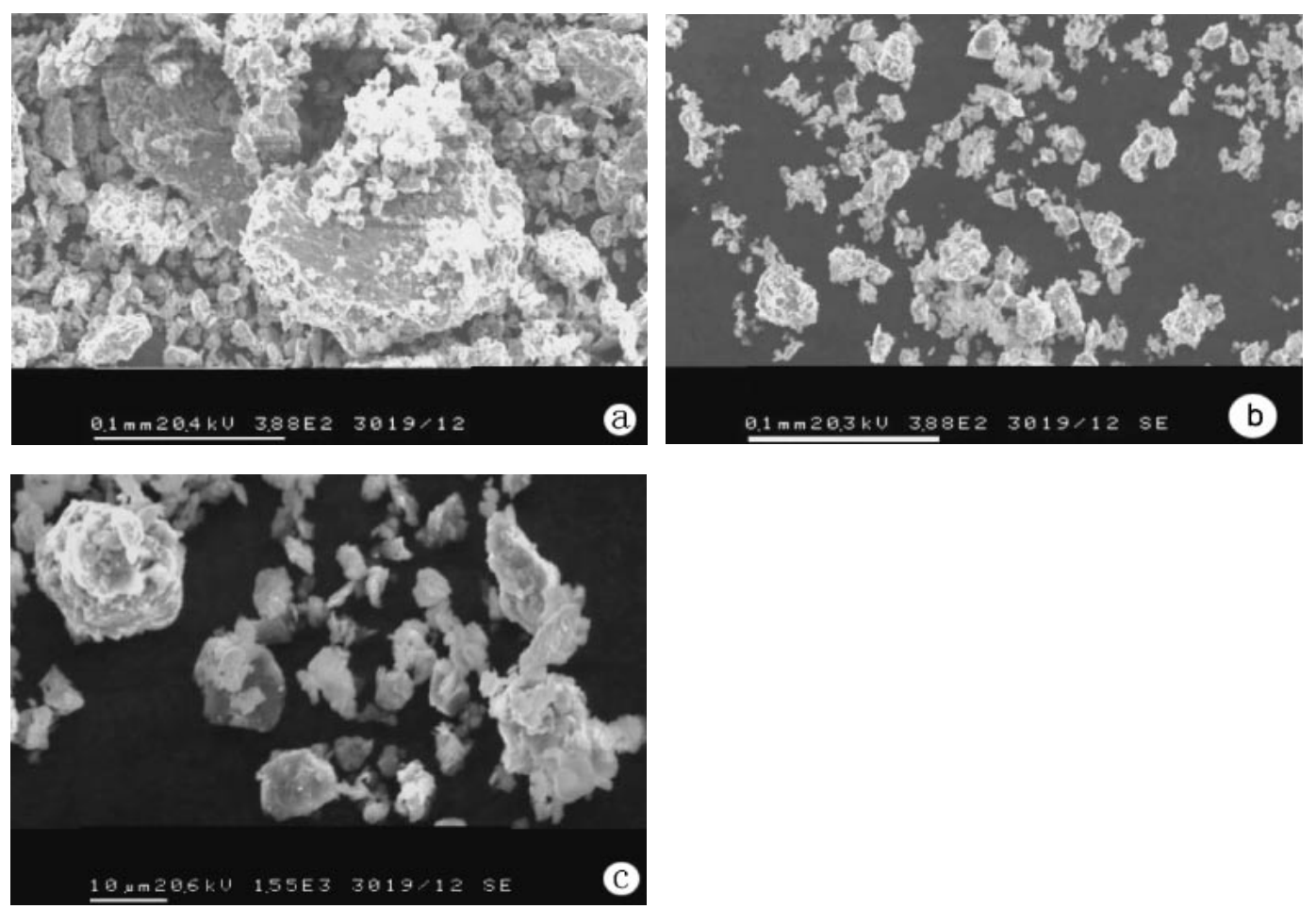

Fig. 1 Morphology of 10 vol $\% \mathrm{~B}_{4} \mathrm{Cp} / 2024 \mathrm{Al}$ milled $5 \mathrm{hrs}$ with different PCA addition. (a) 1 mass $\%$, (b) 2 mass $\%$, (c) 4 mass $\%$.

respectively and the ambient tensile experiment was performed with a constant cross-head speed of $0.5 \mathrm{~mm} / \mathrm{min}$. The fracture surface of the specimen was examined by scanning electron microscopy (SEM).

\section{Results and Discussion}

\subsection{Morphological and microstructural evolution}

It is well known that mechanical alloying involves two opposite processes, namely cold welding and fracturing. PCA is used to nullify the forces of cold welding during MA. The PCA, being absorbed on the surface of the particles, helps inhibit excessive cold welding and therefore agglomeration by lowering the surface tension of the solid materials. $\left.{ }^{15}\right)$ Severely cold-welded and coarse particles were obtained after mechanical alloying of ductile powders such as aluminum (or aluminum alloy), so it is necessary to refine the particle size of system containing ductile matrix by adding PCA (process control agent). In order to evaluate the influence of PCA addition on the size of $\mathrm{B}_{4} \mathrm{C}_{\mathrm{P}} / 2024 \mathrm{Al}$ composite particles, 3 batch of $\mathrm{B}_{4} \mathrm{C}_{\mathrm{P}} / 2024 \mathrm{Al}$ composite with different PCA content were used in this experiment. Figure 1 shows the morphology changes of $10 \mathrm{vol} \% \mathrm{~B}_{4} \mathrm{C}_{\mathrm{p}} / 2024 \mathrm{Al}$ milled 5 hrs with different PCA addition. Some composite powders show a wide size distribution by adding 1 mass $\%$ PCA into the $\mathrm{B}_{4} \mathrm{C}_{\mathrm{P}} / 2024 \mathrm{Al}$ composite mixture, and flakelike powders with a size more than $100 \mu \mathrm{m}$ were still detected (Fig. 1(a)). By contrast, composite powders with 2 mass $\%$ and 4 mass \% PCA addition were revealed refined particle size (size distribution of $10-20 \mu \mathrm{m}$ ) with irregular shape that was subjected to same duration of mechanical alloying.

Polished sections of composite powders containing $10 \mathrm{vol} \% \mathrm{~B}_{4} \mathrm{C}$ particles mechanical alloyed different time are shown in Fig. 2. During the early stage of mechanical alloying, the globular aluminum powders are flattened by the impact action of milling medium, and the size of aluminum particles increases to a big one (Fig. 2(a)). With milling process going on, laminar particles are formed as a result of cold-weld action of the flattened particles. At the same time, $\mathrm{B}_{4} \mathrm{C}$ particles pinned on the surface of the aluminum particles are entrapped between laminar gap (Fig. 2(b)). After $3 \mathrm{~h}$ milling, the composite particles begin to have a equiaxial morphology (Fig. 2(c)), the laminar boundaries are distorted for the competition of cold weld and fracture, and random welding orientation are formed. The steady state is achieved by milling the mixture $5 \mathrm{~h}$ (Fig. 2(d)). The said laminar boundaries are disappeared or not distinguished by the optical microscopy. During this process, the particle size and microstructure are refined.

Figure 3 shows the distribution of $\mathrm{B}_{4} \mathrm{C}$ particles throughout matrix alloy. The results indicate that a homogeneous reinforcement distribution into matrice was obtained and no evidence of agglomerate was detected. The bands lacking of reinforcements are not found in this investigation. And the defects such as voids and porosities are absent in these composite materials.

Clean interfaces of particle reinforced aluminum matrix composites are frequently observed in specimen produced by powder metallurgy method. Mechanical properties of composites are intensively related to the distribution of reinforcements and the interface between reinforcements and matrix alloys. When a clean and strong bonded interface obtained, the applied stress can transfer to the reinforcements effectively, which will benefit the mechanical properties of composites. At the same time, fresh fractured surface of composite powders by mechanical alloying technique can 

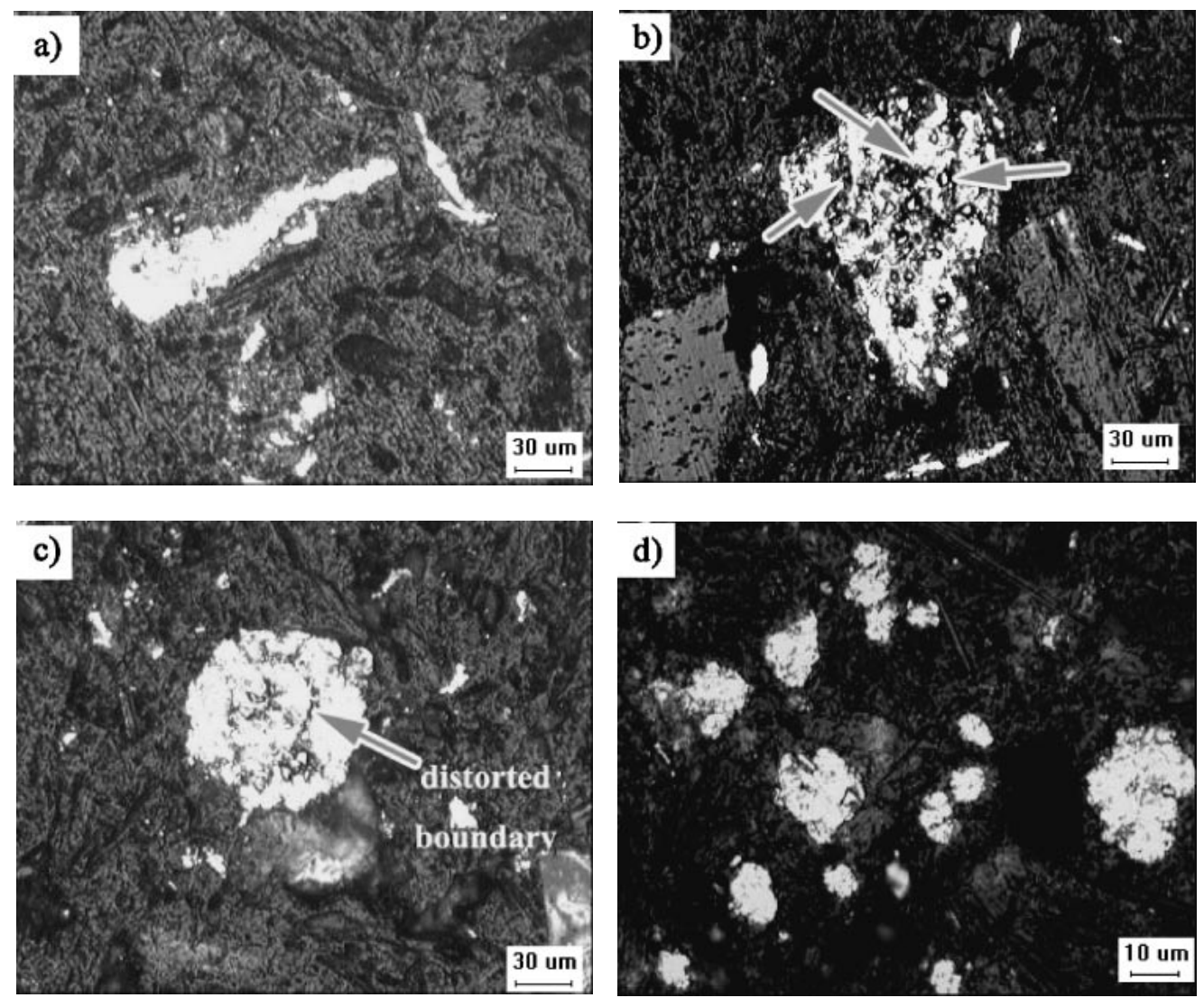

Fig. 2 Sections of 10 vol $\% \mathrm{~B}_{4} \mathrm{Cp} / 2024 \mathrm{Al}$ composite powders milled with different time. a) $1 \mathrm{~h}, \mathrm{~b}$ ) $2 \mathrm{~h}, \mathrm{c}$ ) $3 \mathrm{~h}$, d) $5 \mathrm{~h}$. Boundaries of laminar structure and distorted boundaries of random welded structure were indicated with arrows in Fig. 2(b) and Fig. 2(c), respectively.
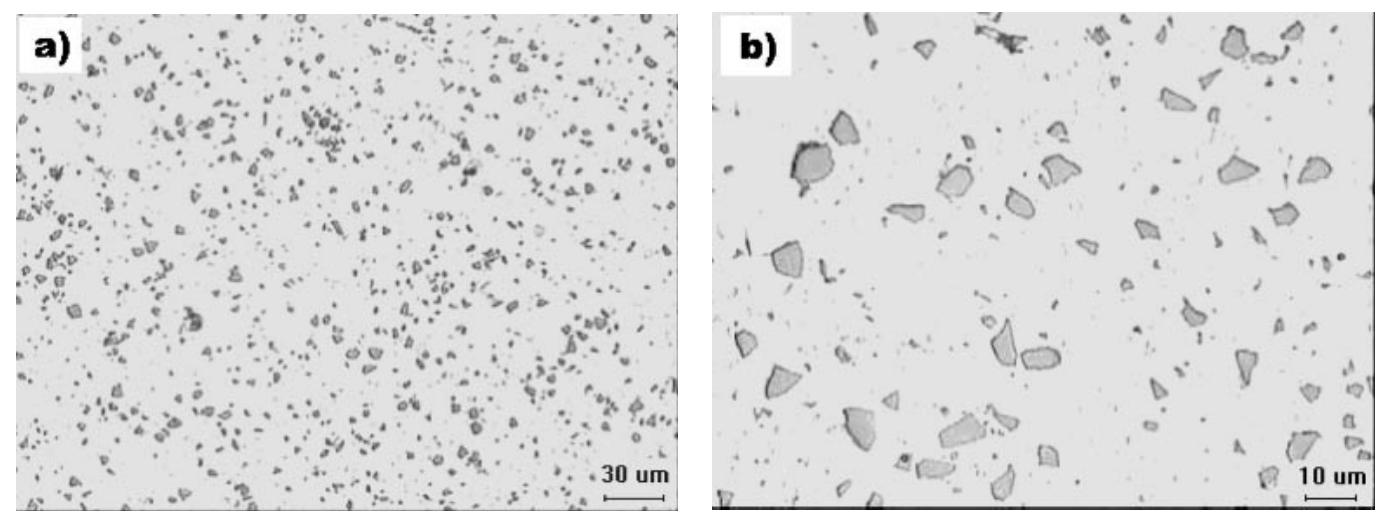

Fig. 3 Optical micrograph of $10 \mathrm{vol} \% \mathrm{~B}_{4} \mathrm{Cp} / 2024 \mathrm{Al}$ extruded specimen, indicating the uniform distribution of $\mathrm{B}_{4} \mathrm{C}$ particles into 2024 matrix alloy. a) low magnification, b) high magnification.

also facilitate the strong metallurgical bonding between reinforcements and based alloys. Figure 4 shows the typical morphology of interface in the $10 \mathrm{vol} \% \mathrm{~B}_{4} \mathrm{C}_{\mathrm{p}} / 2024 \mathrm{Al}$ composites fabricated by mechanical alloying and powder metallurgy technology. No chemical products are formed during the fabrication of composites, and the compounds such as $\mathrm{AlB}_{2}, \mathrm{AlB}_{12} \mathrm{Al}_{4} \mathrm{C}_{3}$ and $\mathrm{Al}_{3} \mathrm{BC}$ are not detected near the interface between $\mathrm{B}_{4} \mathrm{C}$ and $\mathrm{Al}$, indicating that clean interface maintained after the hot pressed and hot extrusion.

Figure 5 shows the typical microstructure of matrix alloy after mechanical alloying and hot extrusion. The average size of sub-grains is near $300 \mathrm{~nm}$, and abundance of oxide (Fig. 6 marked A) and carbide (Fig. 6 marked B) dispersed into the based alloys. Enriched element of $\mathrm{O}$ was found in zone of particle A according to the EDX analysis. And the identification of particle $\mathrm{B}$ was related to the research works of reference ${ }^{16)}$ and reference. ${ }^{17)}$ Oxide can originate from the $\mathrm{Al}_{2} \mathrm{O}_{3}$ film of $\mathrm{Al}$ alloy, which fractured during the mechanical alloying and then incorporated into the matrix during the process of fabrication. The carbide formed as a result of combination of $\mathrm{Al}$ and $\mathrm{C}$ (discomposed from process control agent). More detailed analysis of the $\mathrm{B}_{4} \mathrm{C}_{\mathrm{p}} / 2024 \mathrm{Al}$ microstructures is being carried out at present and will be published elsewhere. 


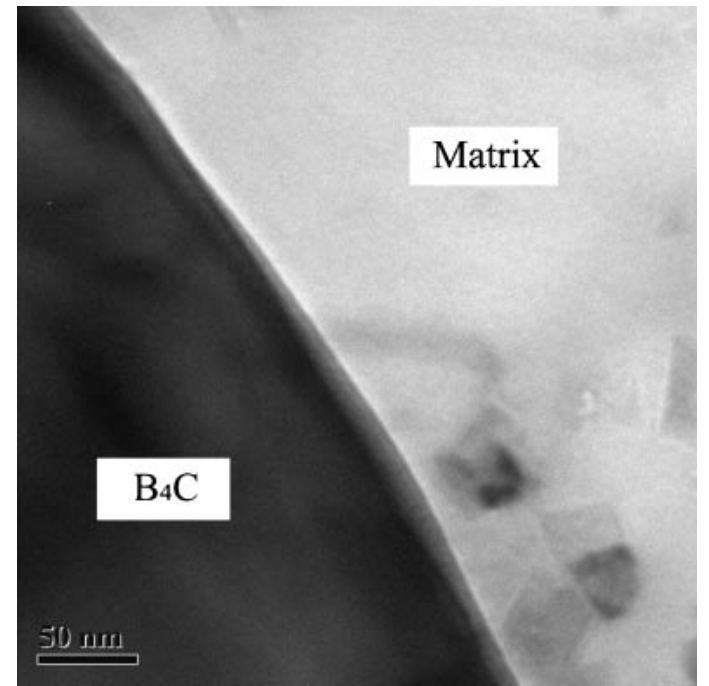

Fig. 4 Interface morphologies in $10 \mathrm{vol} \% \mathrm{~B}_{4} \mathrm{Cp} / \mathrm{Al}$ composites produced by mechanical alloying-hot extrusion technology. Clean and strong bonding interfaces were obtained though mechanical alloying-hot extrusion.

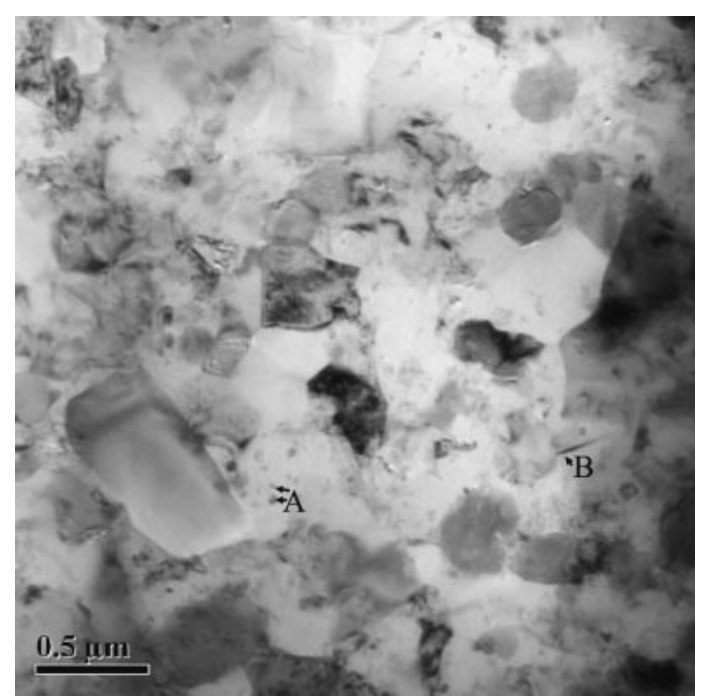

Fig. 5 Microstructure of matrix developed by mechanical alloying and hot extrusion. The presence of oxide (marked with A) and carbide (marked with B) in the matrix alloy.

\subsection{Mechanical properties evaluation}

Table 1 shows that $\mathrm{B}_{4} \mathrm{C}_{\mathrm{P}} / 2024 \mathrm{Al}$ composite with high tensile strength and elastic modulus as compared to their unreinforced alloy. The elastic modulus and UTS of composite materials increased significantly over their based material by adding the $\mathrm{B}_{4} \mathrm{C}$ particles into matrix alloy.

The measured and estimated elastic modulus of composites with volume fraction adding into based alloy is illustrated in Fig. 6. The results show that the experimental values are deviated to the estimated values. For example, the elastic modulus of composite is most commonly estimated by using the rule of mixture (ROM):

$$
E_{c}=V_{p} E_{p}+V_{m} E_{m}
$$

where $E_{m}$ and $E_{p}$ are the Young's modulus of matrix alloy

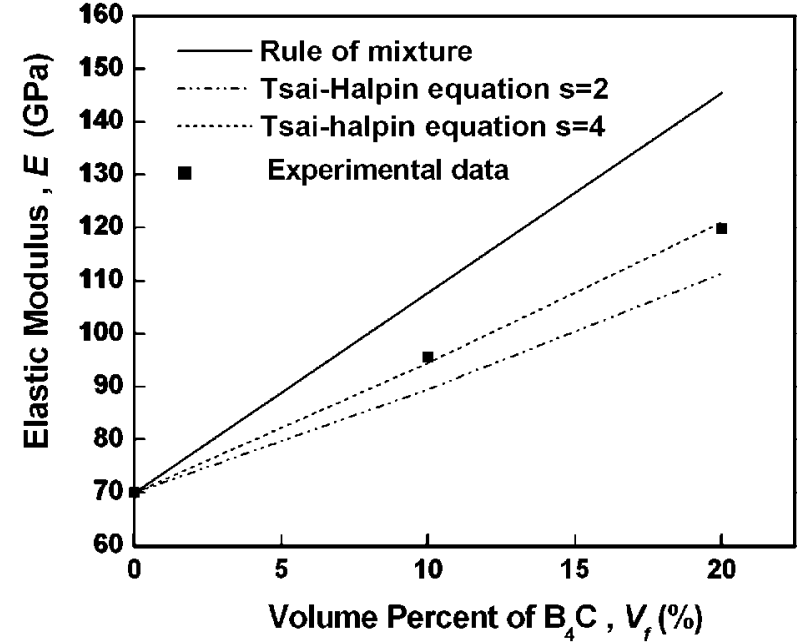

Fig. 6 Theoretically estimated elastic modulus for composites containing different volume fraction of $\mathrm{B}_{4} \mathrm{C}$ reinforcements. The deviation between the experimental results and the theoretical results can be attribute to the formation of oxide and carbide during mechanical alloying.

Table 1 Mechanical properties of composites and unreinforced alloy.

\begin{tabular}{ccccc}
\hline Material & $\sigma_{0.2}(\mathrm{MPa})$ & $U T S(\mathrm{MPa})$ & $E(\mathrm{GPa})$ & $\delta(\%)$ \\
\hline 2024 & 400.8 & 489 & 69.93 & 14.7 \\
10MMC $^{*}$ & 456 & 573.5 & 95.63 & 1.71 \\
20MMC $^{*}$ & 528.1 & 626.7 & 119.8 & 1.645 \\
\hline
\end{tabular}

*10MMC refer to $10 \mathrm{vol} \% \mathrm{~B}_{4} \mathrm{Cp} / 2024 \mathrm{Al}$ matrix composites

*20MMC refer to $20 \mathrm{vol} \% \mathrm{~B}_{4} \mathrm{Cp} / 2024 \mathrm{Al}$ matrix composites

all the specimen in a condition of as-extruded

$\delta$ refer to elongation of composites and monolithic alloy.

and $\mathrm{B}_{4} \mathrm{C}$ particle, and the value of Young's modulus is $70 \mathrm{GPa}$ and $450 \mathrm{GPa}$, respectively. $V_{m}$ and $V_{p}$ are the volume percent of matrix alloy and $\mathrm{B}_{4} \mathrm{C}$ particle, respectively. The remarkable discrepancy of Young's modulus between experimental data and ROM expression indicating that ROM expression is not fitted very well to predict the Young's modulus values of discontinuously reinforced aluminum matrix composites, same results were obtained by other researchers. ${ }^{18)}$ In order to make the modulus of discontinuously reinforced aluminum matrix composites to be predicted well with models, Halpin-Tsai equation was usually adopted: ${ }^{18)}$

$$
E_{c}=\frac{E_{m}\left(1+2 s q V_{p}\right)}{1-q V_{p}}
$$

and $V_{m}=1-V_{p} \cdot q=\frac{\left(E_{p} / E_{m}-1\right)}{\left(E_{p} / E_{m}\right)+2 s} s$ is the particle aspect ratio.

The aspect ratio of reinforcement is about 2 in this experiment, and the experimental value of Young's modulus was higher than concluded values from Halpin-Tsai equation. An enhanced value of Young's modulus indicated that some different strengthening mechanism in composites by high energy milling varied from traditional low-energy millinghot extrusion route. According to this experiment, the formation of oxide and carbide have attribution to the increasing Young's modulus values. The volume fraction of oxide introduced into based alloy through mechanical alloying is estimated about $0.5-1$ pct, ${ }^{16)}$ meanwhile, contri- 


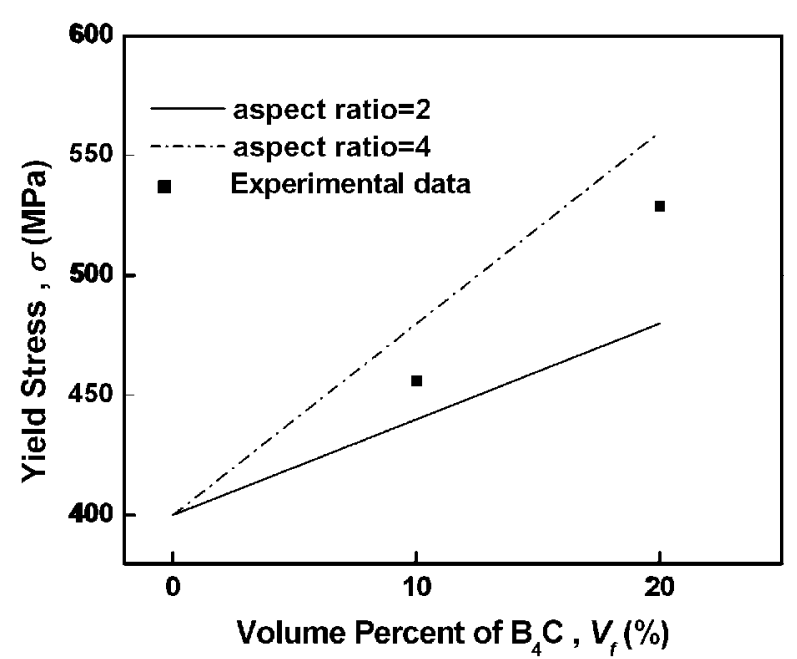

Fig. 7 Variation of yield strength of composites with different volume fraction and aspect ratios of $\mathrm{B}_{4} \mathrm{C}$ reinforcements particles.

bution of dispersed particles (oxide plus carbide, using the value $420 \mathrm{GPa}$ of $\mathrm{Al}_{2} \mathrm{O}_{3}$ ) to increment of modulus is about 2$4 \mathrm{Gpa}$ (volume fraction of dispersed particles multiplication by the Young's modulus of dispersed particles). As a consequence, experimental value of the Young's modulus of composites by MA is higher than the results concluded from eq. (2) by using aspect ratio of reinforcement as value of 2 .

The yield strength of composites can be compared to the theoretical strength using the following relation proposed by Nardon. ${ }^{19)}$

$$
\sigma_{c y}=\sigma_{m y}\left\{\left[V_{p}(1+s / 2)\right]+\left[1-V_{p}\right]\right\}
$$

where $\sigma_{m y}$ is the yield strength of matrix alloy $s$ and $V_{p}$ is the aspect ratio and volume percent of reinforcements, respectively.

Figure 7 shows the predicted and experimental yield strength of the $\mathrm{B}_{4} \mathrm{C}_{\mathrm{p}} / \mathrm{Al}$ composites using equation (3). The yield strength of composites varied significantly as other research works. ${ }^{18)}$

The high values of yield strength of composites processed by mechanical alloying and hot extrusion are contributed to the reason as follows:

1) Particle strengthening from boron carbide;

2) Refinement of grains strengthening induced by high energy milling;

3) Orowan strengthening from the oxide and carbide formed during mechanical alloying.

Boron carbide particles can attribute more strengthening effect to the composites compared to silicon carbide reinforced aluminum matrix composites. ${ }^{20)}$ When tension load applied on the specimen, the tension load can transfers to the reinforcements effectively though interface according to the former analysis.

At the same time, the refinement of based alloy can attribute to the improved yield strength. According to the Hall-Petch equation:

$$
\sigma_{y}=\sigma_{0}+k d^{-\frac{1}{2}}
$$

$d$ is the mean grain size of matrix alloy.

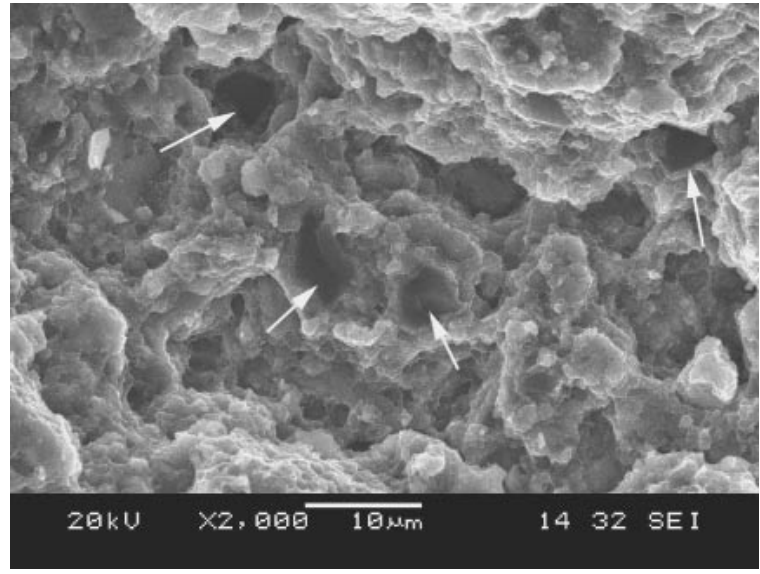

Fig. 8 Fractured surface examination of 10 vol $\% \mathrm{~B}_{4} \mathrm{Cp} / 2024 \mathrm{Al}$ composites. The presence of intact reinforcement particles (marked with inserted arrow) on the fracture surface indicated that bonding between boron carbide and aluminum was good. Dimples presented on the fracture surface indicating that based alloy deformed with a ductile manner in microscopic view.

The yield strength enhanced while the $d$ value decreased. Therefore, the increments of yield strength owing to subgrain $\sigma_{g}=k d^{-\frac{1}{2}}$ induced by high energy milling was estimated about $\Delta \sigma_{g}=182.5 \mathrm{MPa}$ when adopt the value of $\mathrm{k}$ (constant) as $0.1 \mathrm{MPa} \sqrt{m}$.

And the impediment to the movement of dislocations by nanosize oxide and carbide can contribute to increment of yield strength. The fine $\mathrm{B}_{4} \mathrm{C}$ particles from fractured particles during high energy milling acted Orowan mechanism too.

Figure 8 showing the fracture surface of $10 \mathrm{vol} \% \mathrm{~B}_{4} \mathrm{C}_{\mathrm{P}} /$ 2024Al composites. Intact boron carbide particles are presented on the surface of fracture samples, moreover, cracking of reinforcements and decohersion of reinforcement/matrix interface are scarce in our fully examination of fracture surface of $\mathrm{B}_{4} \mathrm{C}_{\mathrm{P}} / 2024 \mathrm{Al}$ composites. The results indicate that the bonding between boron carbide and aluminum is perfect, and the load can be transferred to reinforcing particles through interface. The fracture mechanism of this kind of composites is dominated by the failure of matrix alloy.

\section{Conclusions}

(1) The weight percent of PCA has an influence on the process of mechanical alloying. The particle size decreased when powders were milled $5 \mathrm{hrs}$ with 2 mass $\%$ PCA addition.

(2) A homogeneous distribution of $\mathrm{B}_{4} \mathrm{C}$ particles throughout the matrix was obtained. The defects such as pores and cracks were not detected in the polished specimen by optical microscopy.

(3) A strong interface bonding between $\mathrm{B}_{4} \mathrm{C}$ and $2024 \mathrm{Al}$ was achieved through mechanical alloying and hot extrusion. No chemical products were formed near the interface.

(4) Mechanical properties (such as ultimate tensile strength and Young's modulus values) of $\mathrm{B}_{4} \mathrm{C}_{\mathrm{p}} / 2024 \mathrm{Al}$ composites increased significantly in comparison with those 
un-reinforced alloys. The several models like the ROM cannot be applied to exactly predict the mechanical properties such as Young' modulus and yield strength of the $\mathrm{B}_{4} \mathrm{C}_{\mathrm{P}} / 2024 \mathrm{Al}$ composites produced by $\mathrm{MA}$ technique.

\section{Acknowledgements}

The work of this paper was supported from the Major Fundamental Research Project, Shanghai Science and Technology Committee under Grant No. 04DZ14002 and No. 05JC14024.

\section{REFERENCES}

1) D. J. Llyod: Inter. Mater. Rev. 39 (1994) 1-23.

2) I. A. Ibrahim, F. A. Mohamed and E. J. Lavernia: J. Mater. Sci. 26 (1991) 1137-1156.

3) V. K. Varma, S. V. Kamat, Y. R. Mahajan and V. V. Kutumbarao: Mater. Sci. Engng. A318 (2001) 57-64.

4) A. M. Davidson and D. Regener: Comp. Sci. Technol. 60 (2000) 865 869.

5) G. O’Donnell and L. Looney: Mater. Sci. Engng. A303 (2001) 292301 .
6) X. Zhang and M. J. Tan: J. Mater. Proc. Technol. 63 (1997) 913-917.

7) J. B. Fogagnolo, F. Velasco, M. H. Robert and J. M. Torralba: Mater. Sci. Engng. A342 (2003) 131-143.

8) L. Lu, M. O. Lai and C. W. Ng: Mater. Sci. Engng. A252 (1998) 203211.

9) J. Ye, B. Q. Han, Z. Lee, B. Ahn and S. R. Nutt, J. M. Schoenung: Scripta Mater. 53 (2005) 481-486.

10) D. C. Halverson, A. J. Pysik, I. A. Aksay and W. E. Snowden: J. Amer. Ceram. Soc. 72 (1989) 775-780.

11) A. J. Pyzik and D. R. Beaman: J. Amer. Ceram. Soc. 78 (1995) 305312.

12) J. C. Viala, J. Bouix, G. Gonzalez and C. Esnouf: J. Mater. Sci. 32 (1997) 4559-4573.

13) S.-Y. Oh, J. A. Cornie and K. C. Russell: Metall. Trans. 20A (1989) 527-532.

14) H. M. Hu, E. J. Lavernia, W. C. Harrigan, J. Kajuch and S. R. Nutt: Mater. Sci. Engng. A297 (2001) 94-104.

15) Li Lu and Y. F. Zhang: Journal of Alloys and Compounds 290 (1999) 279-283.

16) H. R. Last and R. K. Garrett: Jr. Metall. Trans. 27A (1996) 737-745.

17) S. K. Kang, D. L. Erich and H. F. Merrick: High-Strength Powder Metallurgy Aluminum Alloys, ed. by M. J. Koczak and G. J. Hildeman (TMS-AIME, Warrendale, PA, 1982) pp. 317-328.

18) R. Angers, M. R. Krishnadev, R. Tremblay, J.-F. Corriveau and D. Dubé: Mater. Sci. Engng. A262 (1999) 9-15.

19) V. C. Nardone and K. M. Prewo: Scripta. Metall. 20 (1986) 43-48.

20) R. U. Vaidya, S. G. Song and A. K. Zurek: Phil. Mag. 70 (1994) 819836. 